\title{
A INFLUÊNCIA DOS BLOGS DE MODA NO PROCESSO DE DECISÃO DE COMPRA DO CONSUMIDOR FEMININO
}

\author{
THE INFLUENCE OF FASHION BLOGS IN THE FEMALE \\ CONSUMER PURCHASE DECISION PROCESS
}

\section{LA INFLUENCIA DE LOS BLOGS DE MODA EN EL PROCEDIMIENTO DE DECISIÓN DE COMPRA DEL CONSUMIDOR FEMENINO}

Carla Cristine Vianna Nogueira

Pesquisadora do Grupo de Pesquisa em Marketing Tecnológico da Universidade da Amazônia (UNAMA) / Graduada em Administração de Empresas pela Universidade da Amazônia (UNAMA), Brasil cvnogueira@yahoo.com.br

\section{Daniele de Oliveira Ferreira}

Pesquisadora do Grupo de Pesquisa em Marketing Tecnológico da Universidade da Amazônia (UNAMA) / Graduada em Administração de Empresas pela Universidade da Amazônia (UNAMA), Brasil danferreira01@gmail.com

\section{Emílio José Montero Arruda Filho}

Professor da Universidade da Amazônia (UNAMA) e da Universidade FUMEC / Doutor em Marketing pela Universidade de Bergamo na Itália, passando um período de 1 ano como visitante na Universidade de Rhode Island nos EUA / Pós-doutor na Fundação Getúlio Vargas (FGV-EAESP) no departamento de Mercadologia, Brasil

emilio.arruda@unama.br
Contextus

ISSNe 2178-9258

Organização: Comitê Científico Interinstitucional Editor Científico: Diego de Queiroz Machado

Avaliação: double blind review pelo SEER/OJS Edição de texto e de layout: Carlos Daniel Andrade

Recebido em 21/06/2017

Aceito em 11/04/2018 $2^{a}$ versão aceita em 19/04/2018

\section{RESUMO}

Este artigo tem como objetivo analisar como o consumidor feminino é influenciado pelo conteúdo publicado nos blogs de moda. Para tanto, examina dois blogs - Entre Topetes e Vinis, voltado ao público plus size, e Garotas Estúpidas, de moda regular -, avaliando se as motivações de cada público são hedônicas ou utilitárias em função do seu perfil de consumo. A pesquisa possui natureza qualitativa e utiliza o método netnográfico, que se baseia em estudos de grupos participantes em comunidades virtuais e/ou sites de discussões da Internet. Os resultados mostram grande influência no processo de decisão de compra no caso do blog plus size, focado nos valores utilitaristas dos usuários, enquanto o blog regular ativa mais uma relação hedônica, servindo para a consulta de informações e para a interação entre grupos. Esse cenário serve de embasamento para que as empresas observem os estímulos e as características de cada consumidor, aproveitando assim todos os benefícios que a mídia social pesquisada oferece para o mercado da moda na atualidade.

Palavras-chaves: Blog. Moda. Plus Size. Intenção de Compra.

\section{ABSTRACT}

This article aims to analyze how female consumers are influenced by contents published in fashion blogs. To do so, it examines two blogs-Entre Topetes e Vinis, oriented towards the plus size public, and Garotas Estúpidas, of regular fashion-, by evaluating if the motivations of each public are hedonic or utilitarian 
according to their profile of consumption. The research has a qualitative nature and uses the netnographic method, which is based on investigating groups that participate in virtual communities and/or Internet discussion sites. The results show a great influence on the purchase decision process in the case of the plus size blog, focused on the users' utilitarian values, while the regular blog activates a more hedonic relationship, serving as a source of information and as a form of group interaction. This scenario serves as a basis for companies to observe the stimuli and characteristics of each consumer, thus taking advantage of all the benefits that the social media researched herein offers to the fashion market today.

Keywords: Blog. Fashion. Plus Size. Purchase Intention.

\section{RESUMEN}

Este artículo tiene como objetivo analizar cómo el consumidor femenino es influenciado por el contenido publicado en los blogs de moda. Para ello, examina dos blogs - Entre Topetes e Vinis, volcado al público plus size, y Garotas Estúpidas, de moda regular -, evaluando si las motivaciones de cada público son hedónicas o utilitarias en función de su perfil de consumo. La investigación tiene carácter cualitativo y utiliza el método netnográfico, que se basa en estudios de grupos participantes en comunidades virtuales y/o sitios de discusiones de Internet. Los resultados muestran una gran influencia en el proceso de decisión de compra en el caso del blog plus size, enfocado en los valores utilitaristas de los usuarios, mientras que el blog regular activa más una relación hedónica, sirviendo para la consulta de informaciones y para la interacción entre grupos. Este escenario sirve de base para que las empresas observen los estímulos y las características de cada consumidor, aprovechando así todos los beneficios que la plataforma aquí investigada ofrece para el mercado de la moda en la actualidad.

Palabras Clave: El blog. La moda. Plus Size. Intención de Compra.

\section{INTRODUÇÃO}

Com o crescimento da tecnologia, a Internet passou a ter papel fundamental no mercado da moda. Observa-se que, no Brasil, essa realidade não é diferente, pois a Internet e as mídias sociais cada vez mais fazem parte do cotidiano das pessoas (MEDEIROS et al., 2014). Conforme o último relatório semestral da Webshoppers, empresa de inteligência e comércio eletrônico [EBIT] que analisa a evolução dessa modalidade de comércio, mais de 55 milhões de consumidores fizeram compras pela Internet em 2017, tendo uma alta de $15 \%$ em relação ao ano anterior. Entre as categorias mais vendidas estão: telefonia/celulares, moda e acessórios, cosméticos, perfumaria e saúde e eletrodomésticos (EBIT, 2018).
Conforme dados da revista Conexão Sebrae (ZARA, 2013), o mercado fashion já possuía, em 2013, uma alta resposta com $13,7 \%$ dos $\mathrm{R} \$ 12,7$ bilhões que circulvaam pela Internet no período pesquisado, o que representa um crescimento de $24 \%$ em relação aos primeiros seis meses de 2012 (SEBRAE, 2013). A Internet continua sendo uma excelente opção para as empresas expandirem seus negócios. Entre as mídias sociais que mais impulsionam esse crescimento, destacam-se os blogs de moda. Segundo Pinto (2002), os blogs ou weblogs são exemplos de espaço virtual que possibilitam a ação em comunidades com outros usuários, com uma interface relativamente fácil de ser aplicada, gratuitos na maioria dos casos, simples de atualizar, de baixo custo e abertos a 
comentários e opiniões que servem de instrumento para melhorar a comunicação com os clientes e consumidores.

Em relação aos blogs de moda, podemos destacar a grande influência que eles exercem sobre o mercado, sendo utilizados por grandes empresas como ferramenta de divulgação de suas marcas para potencializar as vendas. A Technorati Midia, em seu relatório anual de influência digital, divulgado em 2013, afirmou que os blogs eram mais influentes na formação de opinião que o Twitter e, quando se trata de afetar diretamente decisões de compras, são mais importantes que o Facebook. Em relação ao tamanho da comunidade, $54 \%$ dos consumidores afirmam que, quanto menor a comunidade, maior a influência, o que leva os consumidores a voltarem suas pesquisas para os blogs antes de concluírem uma compra. Ainda de acordo com o relatório Technorati, os blogs são a terceira fonte mais influente na mídia digital, com $31 \%$, enquanto os sites de varejo atingem $56 \%$ e os de marcas específicas, $34 \%$.

Nesse cenário, crescentes mudanças que ocorrem no mundo empresarial vêm obrigando as organizações a inserir-se no contexto das novas tecnologias - premissa básica para quem deseja estreitar relações com o seu público-alvo (NANNI; CAÑETE，2010). Durante o processo de compra on-line, ao reconhecerem a necessidade de obter algum produto ou serviço, os consumidores acessam a Internet em busca de informações necessárias relacionadas (MALIK; GUPTHA, 2013).

Porém, possuir uma grande quantidade de acesso aos sites ou um grande número de likes em uma determinada publicação não é garantia de venda. O objetivo é que as pessoas curtam, compartilhem e, por fim, efetivem a compra. Assim, a questão a analisar é: qual a real influência e efetividade das mídias sociais, em particular os blogs, na decisão de compra do consumidor de produtos de moda?

Para tanto, este artigo pretende analisar quais são as principais motivações dos consumidores ao consultarem os blogs de moda como ferramenta para uma possível compra. É necessário compreender se as motivações de consulta dos blogs são hedônicas - que proporcionam prazer, diversão e satisfação no contexto do uso (OKADA, 2005) - ou utilitárias - em que o uso do produto está relacionado de forma mais racional a uma necessidade individual ou coletiva (SLAMA; SINGLEY, 1996). Cumpre também entender como os blogs de moda influenciam o comportamento do 
consumidor, sendo aquelas características determinantes ou não para a efetividade da compra on-line.

Em tal cenário, serão analisados os blogs de moda Garotas Estúpidas, voltado para o segmento de moda regular, e Entre Topetes e Vinis, direcionado ao segmento plus size, com o objetivo de entender o papel que os blogs voltados para a moda feminina possuem no comportamento de compra e consumo na era digital, possibilitando que as empresas identifiquem os melhores caminhos para atingirem o seu público-alvo de acordo com o perfil de consumo e tipo de produto procurado.

Assim, será realizada uma pesquisa qualitativa, utilizando a netnografia, que consiste na participação, extração e análise de informações de blogs ou fóruns de discussões de uma determinada cultura (KOZINETS, 2002), para realizar a análise de conteúdo dos dados coletados para a pesquisa sobre o argumento de estudo.

$\mathrm{O}$ artigo foi dividido em seis tópicos. Após a introdução, que apresenta a contextualização do trabalho e dados de mercado, apresenta-se o referencial teórico dividido em duas seções, sobre o histórico da moda, o conceito de blogs e a importância das mídias sociais diante do mercado, avaliando como o comportamento do consumidor se orienta perante essas ferramentas digitais e quais motivações hedônicas e/ou utilitárias mais influenciam o cenário. Em seguida, descreve-se a metodologia utilizada, expondo de forma detalhada o conceito de pesquisa netnográfica, o procedimento e a coleta de dados. Para o resultado da pesquisa, são criadas as categorias e subcategorias de análise do perfil dos usuários, organizando os interesses e valores por grupos heterogêneos. A conclusão apresenta as limitações, a discussão do alcançado e projetos futuros.

\section{CONSUMO DE MODA}

Considerado recente, o conceito de moda surgiu entre o fim da Idade Média e o início da Renascença, no século XV. A palavra moda provém do latim mos, que significa costume, tradição, uso. Em 1928, Dr. Paul H. Nystrom definiu moda como "nada mais, nada menos que o estilo predominante em qualquer momento específico" (Cobra, 2008, p. 10), simbolizando relações de imagem e identidade do indivíduo com o seu vestir. Ao longo dos séculos, as pessoas têm utilizado as roupas como forma de comunicação não verbal, a fim de expressar posição social, cultural, tribos, preferências religiosas, tudo isso para se 
adequar a situações ou lugares distintos, ou por mera questão de conforto.

$\mathrm{Na}$ última década, a moda deixou de ser relacionada apenas ao vestuário e hoje engloba outros segmentos como acessórios (relógios, joias, canetas, celulares), cosméticos, móveis e artigos para casa, música, dentre outros. Isso se explica por mudanças ocorridas no estilo de vida da sociedade. Segundo Cobra (2008), o estilo de vida pode ser definido como a junção das características individuais e comportamentais com a realidade de vida de cada um.

Com o passar dos anos, a moda evoluiu ao ponto de hoje tomar conta do mercado global, pois estimula o consumo. Para gerir o negócio da moda, é fundamental entender por que ocorre aquele incentivo. Hoje a moda é sobretudo consumo, seja de objetos ou de ideias, e depende mais das escolhas de cada indivíduo. Segundo Goswami (2015), consumidores começam a dar cada vez mais valor à marca e à experiência on-line, de modo que as empresas buscam direcionar mais ainda seu foco de mercado e fortalecendo a marca através do cenário on-line.

\subsection{O fenômeno dos blogs de moda}

Os blogs são espaços para discussão e liberdade de opinião. Por serem ferramentas práticas, popularizaramse, e as blogueiras tornaram-se formadoras de opinião (MESQUITA, 2012). Com a evolução da Internet em termos de qualidade, velocidade e interação, os blogs estão sendo utilizados como nova mídia, ou seja, um veículo de comunicação com o leitor ou clientes.

A ascensão dos blogs possibilitou que qualquer um pudesse compartilhar suas ideias sobre moda e estilo, e essa é uma das principais razões pela qual as blogueiras de moda ganharam prestígio na Internet. Hoje são presenças constantes nas semanas de moda por todo o mundo, sendo a rapidez na informação uma grande vantagem dos blogs em relação às revistas, pois as blogueiras podem publicar em tempo real as notícias e fotos.

Elas conquistaram milhares de seguidores, tornando-se ícones fashion e formadoras de opinião, bem como chamando atenção da mídia tradicional e, especialmente, do mercado de moda e beleza. Além de um meio de comunicação, o blog tornou-se uma poderosa ferramenta mercadológica, em que grandes marcas e estilistas enxergaram um termômetro de 
popularidade e uma nova forma de publicidade (FERREIRA; VIEIRA, 2007).

Atualmente, ser blogueira tornou-se uma rentável e almejada profissão, tão glamorosa quanto de celebridades, já que hoje grandes marcas de roupas e cosméticos direcionam parte de sua publicidade para os espaços reservados com anunciantes dentro dos blogs, principal fonte de renda das blogueiras profissionais.

Um exemplo é o caso do blog Garotas Estúpidas, criado pela pernambucana Camila Coutinho, designer de moda por formação. Possui uma média de 6 milhões de acessos/mês e está em sétimo lugar no ranking dos 99 blogs de moda mais influentes do mundo (SIGNATURE9, 2015). O blog foi criado em julho de 2006, com a intenção de sempre "dividir com as amigas as novidades de moda, beleza e celebridades, sem ninguém que atrapalhasse dizendo que aquilo era tudo bobagem ou futilidade" (COUTINHO, 2012).

Para diversificar a pesquisa, tomouse como segundo exemplo um blog que segue pela contramão dos padrões impostos pela mídia: o Entre Topetes $e$ Vinis, criado em 2009 pela jornalista paulistana Juliana Romano, de 26 anos, primeira mulher plus size a estampar a capa da revista feminina Elle.
O mercado plus size é um mercado em ascensão, prova do que é o evento Fashion Weekend Plus Size, que reúne milhares de pessoas todos os anos. Grandes lojas como C\&A, Marisa, Renner e Riachuelo, assim como grifes como Duloren, Nem e Armazém Erva Doce já estão investindo em coleções voltadas para esse público.

Entretanto, a utilização de blogs como ferramentas para estratégia de marketing deve ser bastante planejada, pois certos blogs podem não se alinhar com o perfil das marcas anunciantes. A força deles está na possibilidade de que seus autores se utilizem dessa ferramenta para beneficiar ou comprometer uma corporação, o que pode representar oportunidades ou ameaças para as empresas (ROSA, 2015).

\subsection{Características de consumo e as mídias sociais}

É de suma importância para as empresas compreender o perfil do consumidor de moda, já que esse entendimento leva a um negócio ideal, tanto nos direcionamentos das vendas quanto na fabricação de peças (produtos) adequadas. Além disso, é possível criar estilos a partir dos gostos dos 
consumidores, utilizando a percepção de valor que os consumidores possuem.

De acordo com o Relatório de Inteligência Sintético (SEBRAE, 2013), outras variáveis se somam, tais como sazonalidade, impulso, vaidade, estética, dentre outros. A compra de vestuário está fortemente ligada às tendências, características físicas, aceitação social e aspectos comportamentais do usuário, tornando-se um desafio que precisa ser desvendado pelo empresário de moda.

É importante também compreender o que leva uma pessoa a comprar determinado produto. $\mathrm{O}$ processo de decisão de compra envolve: necessidade, informação, avaliação, decisão e póscompra. Há dois tipos de fatores para a decisão de consumo: fatores internos (motivação, aprendizagem, percepção, atitudes e personalidade) e externos (família, classe social, grupos de referência e cultura) (MELO; ROCHA, 2011).

Outros aspectos relacionados ao comportamento de compra das pessoas estão relacionados com o hedonismo e o utilitarismo. O consumo hedonista é aquele voltado para satisfazer os desejos do consumidor pelo simples prazer que oferecem e não pela utilidade que os produtos ou serviços venham a possuir. $\mathrm{O}$ valor hedonista de um produto é caracterizado pelo prazer dos sentidos, que propiciam estímulos emocionais (SHETH,

MITTAL, NEWMAN, 2001).

Características hedônicas influenciam os usuários com base em sentimentos, emoções e impulsos que ativem percepções de imediatismo nos consumidores (BATRA; AHTOLA, 1990; KHAN; DHAR; WERTENBROCH, 2005). As relações de afeto, diversão, prazer, felicidade e satisfação ganham no ambiente on-line maior atratividade, pois ele reduz a sensação de culpa percebida, extremamente comum na compra de produtos caros e hedônicos (ARRUDA FILHO; SANTOS; BRITO, 2015).

O utilitarismo, por sua vez, é definido como consumo voltado para a funcionalidade do produto e seus benefícios, uma forma racional de escolha (FOXALL; YANI-DE-SORIANO, 2005). A busca pela melhor relação custobenefício, bem como a usabilidade de um consumo justificam a necessidade deste, em uma situação sem impulsividade, pois desistir de uma compra é bem fácil para consumidores que buscam a utilidade adequada de um produto ou serviço (OKADA, 2005).

Segundo Kunst e Rocha (2012), existem muitas pesquisas sobre insatisfação do consumidor com produtos de moda, sugerindo portanto $o$ desconhecimento por parte das empresas 
de moda sobre as necessidades dos consumidores. Isso ocorre porque os empresários devem procurar entender $\mathrm{o}$ consumidor em relação às características que levam aos seus desejos e necessidades, distinguindo claramente as relações racionais e emocionais com o consumo.

Na última década, as mídias sociais vêm sendo grandes influenciadoras quando se fala em comportamento do consumidor, influenciando as relações de preferências dos consumidores (ARRUDA FILHO; SANTOS; BRITO, 2015). Segundo Lippert (2013), a mídia social é um meio de interação social por meio da web, com o objetivo de permitir uma livre troca de ideias além de gerar conteúdo relevante com base nos usuários.

A Netbase, uma empresa americana especializada em análise de mídias sociais, conduziu uma pesquisa junto a 1.005 mulheres americanas que possuíam perfil em pelo menos uma rede social e investigou a influência das mídias sociais sobre o comportamento das mulheres interessadas em informações sobre moda. O estudo identificou dois segmentos de consumidoras cujo comportamento de compra é mais fortemente influenciado pelas mídias sociais.

O primeiro é o das "Fashionistas", representando $28 \%$ do total. Este grupo é composto pelas mulheres que concordam fortemente com esta afirmação: "Moda e beleza são extremamente importantes para mim”, característica com divergências de valores, podendo ser extremamente hedônica e social, quando a beleza e a moda são características de prazer e identidade, ou podendo ser extremamente utilitária, demonstrando a importância como um contexto de um posicionamento profissional, necessidade de ambientação e qualidade em seu ambiente pessoal (KHAN; DHAR; WERTENBROCH, 2005). O segundo grupo é o das "Compradoras sociais", representando $15 \%$ do total e composto pelas mulheres que concordam fortemente com a seguinte afirmação: "As marcas e produtos que meus amigos usam influenciam minhas decisões de compra”, característica extremamente hedônica e social, o que demonstra o desejo no contexto do consumo (OKADA, 2005). Existe ainda a possibilidade de os dois segmentos terem intermediações: certos consumidores buscam o valor hedônico, mas precisam justificar seu sentimento de culpa; outros buscam o valor utilitário, que entretanto precisa também trazer satisfação para garantir o consumo.

Neste ambiente, as mídias sociais que mais influenciaram nesses dois grupos foram o Facebook, os blogs e 
Fóruns, Pinterest, Instagram e Twitter. Assim, por meio desta pesquisa, observouse claramente que a estratégia a ser adotada pelas empresas consistia em estar presente nas redes sociais, com uma sólida base de conteúdo informativo para atrair as consumidoras fashionistas e compradoras sociais.

De acordo com pesquisa publicada na Revista Exame (2012), o setor de moda era o que mais interagia nas ações digitais, com um índice de 25,5\%, seguido pelo de eletrônicos com 14,3\% e comunicação com 11,3\%.

Ao decidirem efetivar uma compra on-line, os consumidores buscavam na rede informações sobre os produtos ou serviços que desejavam, porém acabavam sendo, muitas vezes, atraídos também por produtos que, embora não fossem o foco principal da busca por informações, eram associados ao bem específico (MALIK; GUPTHA, 2013).

Para este produto em específico de artigos de moda, as mulheres são as mais interessadas nas compras via Internet do que os homens, pois passam mais tempo navegando, buscando mais opções disponíveis, ao contrário dos homens que são mais objetivos. Segundo dados da revista Ebit, o crescimento do ecommerce no Brasil desde 2001 foi de mais de $2.000 \%$ e mais da metade dos e- consumidores que realizaram compras pela Internet foram mulheres (EBIT, 2018).

\section{IDENTIDADE DE CONSUMO E CARACTERÍSTICAS COMPORTAMENTAIS}

Segundo estatísticas e análises de especialistas, o potencial de lucro de um mercado plus size é bastante elevado, porém designers e varejistas do setor de vestuário ainda se mostram ambivalentes ao servir o mercado plus size (EUROMONITOR, 2009). Os comerciantes alegam que a criação de roupa para mulheres maiores requer investimentos em padrões e tecidos diferentes dos utilizados em mulheres pequenas ou médias (CLIFFORD, 2010).

A escassez de produtos plus size e o fato de esses consumidores não serem atendidos pelo varejo deve-se ao fato de serem estigmatizados pelo mercado (SCARABOTO; FISCHER, 2013). Um determinado grupo de consumidores é considerado estigmatizado se, dos discursos ideológicos, emergem avaliações negativas e estereotipadas em relação a este grupo (SANDICKI; GER, 2013). De acordo com Goffman (1986), gordura é considerado um atributo de descrédito, um estigma físico e de caráter. 
Desde que se iniciou a produção em massa de roupas femininas, as ofertas para as mulheres plus size têm sido limitadas em relação à quantidade de pessoas que se encaixam neste perfil, e historicamente estas consumidoras se sentem carentes (STEARNS, 1997).

Para Bourdieu (1993), a alta costura é considerada produto artístico "puro", enquanto a moda plus size é considerada por ele bens culturais "comerciais". Essa ideia talvez consiga explicar por que o estilista Karl Lagerfeld ficou ofendido com a decisão da $\mathrm{H} \& \mathrm{M}$, cadeia de lojas populares para qual produziu uma coleção, de confeccionar roupas em tamanhos maiores: "O que eu projetei era moda para delgados e pessoas magras" (Vogue Reino Unido, 2004).

Ao observar a escassez dos produtos de moda, as consumidoras plus size se uniram num esforço para aumentar sua inclusão dentro do mercado e as opções disponíveis para elas. A esta junção de identidade, baseado nos desejos e necessidades que elas compartilham, chamamos coletivo (SCARABOTO; FISCHER, 2013). A interação é necessária para a formação da identidade coletiva (WHITE, 1992). É percebida uma distinção entre grupos, os quais desvalorizam um grande potencial de consumidores por não se adequar a um contexto mais amplo.

O surgimento de uma identidade coletiva aumenta a chance dos consumidores perseguirem o que eles acreditam que o mercado deve fornecerlhes (SCARABOTO; FISCHER, 2013). Um elemento importante nesta busca por inclusão é o acesso aos blogs especializados em moda plus size. Estas blogueiras são amantes da moda e se autodenominam "Fatshionistas" (SCARABOTO; FISCHER， 2013). Fatshionista é junção da palavra fat, que em inglês significa gordo, com a palavra fashionista, utilizada para nomear um seguidor da moda (MERRIAMWEBSTER, 2010). Acaba assim construindo-se um cenário específico para este novo grupo de consumidores (PETERS, 2014) em função de sua identidade de consumo.

Neste ambiente, as blogueiras têm um impacto visível no mercado da moda (WILSON, 2009), enquanto os fatshionistas não desejam mudar para se adequar ao mercado, mas sim que o mercado se adeque ao seu tamanho e atenda aos seus gostos e necessidades (SCARABOTO; FISCHER, 2013). Com efeito, os blogs possibilitam que esse movimento ganhe força e popularidade (COOPER, 2009). 
As blogueiras atuam como empreendedoras institucionais inspiradoras, ou seja, pessoas capazes de mudar aspectos de domínio institucional e que por vezes são bem-sucedidos, já que os consumidores são inspirados por aqueles que consideram semelhantes a eles em alguns aspectos (SCARABOTO; FISCHER, 2013). No Brasil, podemos destacar, como figura inspiradora para as consumidoras plus size, Juliana Romano autora do blog Entre Topetes e Vinis. Juliana já assinou uma coleção para rede de lojas Marisa, foi capa da Revista Vogue on-line em maio de 2015, entre outras importantes ações na área.

Neste cenário, por conseguirem atingir um público muito vasto, as blogueiras acabam tendo uma grande influência no mercado, fazendo com que grandes marcas queiram se aliar a elas de modo que consigam atender as necessidades deste público e consequentemente consigam alavancar seus lucros.

Desta forma, observamos que estas consumidoras possuem, possivelmente, motivações utilitárias em relação ao consumo da moda plus size, pois o interesse é satisfazer necessidades de vestir-se, mesmo que em alguns pontos busque-se valores de beleza e status. É claro que atender as necessidades básicas envolveria relações mais claras de utilitarismo no consumo, mas um mix de relações entre atendimento das necessidades e atendimento emocional buscando fazer parte do resto da sociedade demonstra a prioridade utilitária a frente da decisão, seguida da hedônica para conclusão do consumo (BATRA; AHTOLA, 1990).

Sabemos que o vestuário é uma necessidade, já que tem a função de proteger o corpo, porém se as funções do corpo fossem reduzidas a apenas satisfazer esta necessidade fisiológica, a formatação e padronização não teria valor (LIMA, 2010). Entretanto, as necessidades delas vão além, sendo também psicológicas, que surgem quando se deseja algo necessário aos valores pessoais e sociais, mas não se tem acesso a isso, iniciando assim o processo de motivação. Quanto maior a distância entre o desejado e o estado atual, maiores são as necessidades e a urgência em satisfazê-la (KARSACLIAN, 2000).

Embora, no que se refere à moda, as necessidades hedônicas (prazerosas e emocionais) e utilitárias (funcionais) caminhem simultaneamente, as necessidades das consumidoras do mercado plus size possivelmente são mais utilitárias do que hedônicas, o que é justificado pela escassez de oferta destes produtos. 
De acordo com De Carli (2002), a moda é uma necessidade, já que hoje em dia não podemos abrir mão da estética no vestir. As funcionalidades da roupa (abrigo, proteção térmica, resistência) evoluem para funcionalidades mais sofisticadas.

Outro tipo de consumidoras que a pesquisa buscou observar foram aquelas também interessadas em moda, porém que possuíam manequim até o tamanho 42, denominadas "regulares". Estas consumidoras não sentem o impacto da escassez de produtos de moda, mas ao contrário, já que este é o padrão de beleza difundido nos meios de comunicação.

Ao contrário das motivações observadas nas consumidoras plus size, as motivações destas consumidoras regulares são possivelmente, em sua maioria, hedônicas. O consumo hedonista, sendo o consumo de produtos ou serviços pelo prazer intrínseco que oferecem, e não para resolver algum problema no ambiente físico (ZAMBERLAN et al., 2010), é evidente neste grupo de consumidoras, pela facilidade de encontrar produtos, onde a participação nos blogs é pela atualização, novidade e diferenciação do que as demais pessoas possuem (HARJU, 2015).

Logo, vivemos em uma economia de transitoriedade (SIQUEIRA, 2007), onde os indivíduos são envolvidos por imagens e objetos que evocam sonhos e desejos em um universo desenfreado de aquisições (ZAMBERLAN et al., 2010). Sobre este universo desenfreado de aquisições, Rocha (2005) complementa dizendo que consumir qualquer coisa é como um passaporte para a eternidade. Busca-se o prazer por meio das emoções, imagens e representações dos produtos e seus significados (CAMPBELL, 2001).

Outras razões envolvem o motivo pelo qual as pessoas compram determinado produto: “o que vestimos são sistemas de símbolos onde os significados nos posicionam como sujeito" (WOORDWARD, 2000). Esta posição está relacionada intimamente ao poder e status social. Assim, estar na moda remete às relações de poder através do que nossa vestimenta representa para os demais (HAMESTER; MORAES, 2011).

O ambiente da moda incentiva o egocentrismo e a vaidade, fazendo com que as consumidoras busquem meios de conseguir uma proximidade com uma imagem dita como "perfeita".

$$
\text { Hamester e Moraes (2011) }
$$

complementam:

\footnotetext{
Neste processo, o papel da mídia se revela como propagadora de um consumo que "promete" poder e pertencimento social, engendrado ideologicamente nas relações, dissemina-se como produto final que chega as massas, que incentiva o poder de compra, enfim, torna-se condição importante da dinâmica de inclusão social.
} 
Neste contexto, os blogs de moda voltados para consumidoras "regulares" e que divulgam, em sua maioria, produtos de luxo, assumem uma ligação direta com esta sensação de poder e pertencimento social. Estas blogueiras têm primeira fila garantida nos principais desfiles e podem ser vistas até mesmo estrelando campanhas de moda (MEDEIROS et al., 2014). Entre elas a própria Camila Coutinho já citada, do blog Garotas Estúpidas, já emprestou seu nome para grandes marcas como Dumont, Riachuelo e outras.

Grande parte dos produtos divulgados por esse tipo de blog e mesmo nas composições de look do dia não patrocinados são produtos de luxo, marcas muitas vezes inalcançáveis por grande parte das leitoras. Porém, as marcas de luxo remetem a benefícios ditos "experienciais", ou seja, o cliente busca experiências e emoções fortes excepcionais (LIPOVETSKY, 2008). A justificativa para o grande número de acessos destes blogs, embora seu conteúdo seja distante da realidade da maioria, é dado pela necessidade de inserção social, já que a ação midiática assume o papel de provocador dos desejos e das vontades individuais (HAMESTER; MORAES, 2011).

Estabelece-se assim um novo tipo de cultura de luxo, em que as estratégias de consumo no campo da moda são alavancadas pela ação da mídia, que tem a função de multiplicar o poder de sonho e desejo a partir de novas plataformas de comércios de bens de luxo (HAMESTER; MORAES, 2011).

A partir das observações desses tipos distintos de blogs, expostos ao longo do artigo, a pesquisa buscou verificar qual dos blogs possui maior influência sobre o consumidor e, de modo mais geral, qual a real influência e efetividade das mídias sociais, em particular os blogs, na decisão de compra do consumidor de produtos de moda.

\section{MÉTODO}

Foram definidos como objeto de análise dois blogs com conteúdo voltado para a moda. A importância da definição do objeto de estudo é de fazer um comparativo em função da diversificação do produto, pois no estudo inicial para compreender tal setor de moda feminina, foi identificado que os consumidores de moda plus size têm dificuldades de encontrar aquilo de que precisam. Logo, identificar quais blogs proporcionam maior estímulo para a compra ou compreender se estes serviam apenas como referência pôde situar as diferentes utilidades do blog em função do perfil de usuário. 
Para analisar a influência dos blogs de moda no processo de decisão de compra do consumidor feminino, desenvolveu-se uma pesquisa qualitativa utilizando a netnografia para coleta de dados, que consiste em extrair informações de blogs/fóruns de discussões sobre os temas de interesse (KOZINETS, 2002). Este método é uma adaptação da pesquisa etnográfica (NEVES, 1996), em que esta foi adequada a realidade virtual, analisando em um cenário livre de influências, os comportamentos dos usuários que participam das comunidades instaladas nos espaços eletrônicos.

Com a ascensão das primeiras comunidades virtuais, no final dos anos 80, a Netnografia pôde emergir como modelo de pesquisa (AMARAL; NATAL; VIANA, 2008). O método proporcionou estudos relevantes em diversas áreas da ciência, revelando inclusive, questões importantes para a área do Marketing, pois a forma simplificada, rapidez e o fato da pesquisa ser pouco invasiva faz deste método uma opção mais compatível para a realização de pesquisas profundas, realizadas em grupos instalados na web (SCARABOTO, 2006). Por meio da netnografia consegue-se observar em um espaço livre, a satisfação/insatisfação da decisão de compra ou uso de um produto ou serviço (comportamento, desejo, necessidade e intenção) (VAN DER HEIJDEN, 2004). Além disso, é mais rápida e menos dispendiosa que outros métodos qualitativos (KOZINETS, 2002). É necessário que os blogs/fóruns de discussão sejam confiáveis, ou seja, de boa reputação pelos usuários e leitores da rede, para que haja maior credibilidade quanto à legitimidade dos comentários analisados.

Existem inúmeros trabalhos que utilizam a netnografia, dentre os quais se destacam o de Arruda Filho, Cabusas e Dholakia (2008), que mostra o comportamento do consumidor tecnológico em relação ao uso do iPhone, e o de Scaraboto e Fischer (2013), que investigou como os consumidores marginalizados se mobilizam para buscar uma maior inclusão nos mercados tradicionais. Nesta análise, é avaliada a decisão, baseada na influência dos fatores hedônicos e utilitários sobre a escolha e preferência de compra.

\subsection{Amostra}

Foram analisados os conteúdos discutidos nos comentários feitos por 282 usuários, em 40 posts, de 2 blogs, voltados a diferentes grupos de consumidores: o blog Garotas Estúpidas, de moda regular, e o blog Entre Topetes e Vinis, voltado a consumidoras plus size, para que houvesse 
uma variedade maior de comentários a serem analisados, com usuárias de diferentes faixas etárias e padrões de uso. Isto permitiu avaliar, de forma confiável, como se dá o processo de decisão de compra baseado na influência de fatores hedônicos e utilitários da rede.

\subsection{Procedimentos de coleta e análise de dados}

Foram copiados e colados em um documento Word, os comentários dos usuários que se encontravam nos blogs estudados. De tais informações coletadas, foram dispostas as 40 discussões mais relevantes, com o título e seus respectivos comentários, ocupando 40 páginas do documento, sendo que o conteúdo ocupou 2/3 de cada página, e o espaço restante de 1/3 foi utilizado para análise (análise manual de conteúdo).

Após a coleta dos dados, os responsáveis pela pesquisa fizeram as análises dos comentários separadamente, interpretando os dados de cada blog de acordo com suas experiências, pontos de vistas e sentimento sobre o conteúdo. Em seguida os dados foram codificados, categorizados e interpretados com comparações entre os autores e suporte pela literatura para comprovar a pesquisa desenvolvida.

A escolha dos blogs é determinada pela qualidade das discussões inicialmente interpretadas, assim como a procedência do responsável pelo blog e pelas discussões. Os blogs utilizados para a pesquisa possuíam uma grande quantidade de informações para analisar e compreender como estas consumidoras (ou categorias de consumidoras) se comportavam mediante aos produtos de moda expostos em cada blog.

Após a organização dos dados foram concebidas as primeiras tabelas do estudo. A Tabela 1 apresenta os endereços eletrônicos dos blogs utilizados, o período de coleta em cada blog e a quantidade de discussões analisadas.

A Tabela 2, referente ao blog Entre Topetes e Vinis, disponibiliza a quantidade de enredos, definidos a partir do agrupamento de discussões com o mesmo tema, os números de discussões analisados, e o número de pôsteres totais referentes a cada discussão. Os pôsteres totais são todos os comentários deixados para cada tema, com alguns indivíduos apresentando mais de uma vez a participação, aumentando assim o valor total de discussões. 
$\underline{\text { Tabela } 1 \text { - Dados primários da pesquisa }}$

\begin{tabular}{c|c|c} 
Nome/URL & Período de coleta (ano 2015) & $\mathrm{N}^{\circ}$ de discussões \\
\hline Garotas Estúpidas http://www.garotasestupidas.com/ & 15 de julho até 15 de setembro & 13 \\
\hline Entre Topetes $e$ Vinis http://juromano.com/ & 15 de julho até 15 de setembro & 27 \\
\hline TOTAL: & & \\
\hline
\end{tabular}

Fonte: Elaboração própria (2015) com base no Banco de Dados Netnográfico.

Tabela 2 - Divisão do enredo desenvolvido para dar suporte à pesquisa (Entre Topetes e Vinis)

\begin{tabular}{c|c|c|c|c}
\hline \multirow{2}{*}{ Objeto } & Nome do enredo & $\mathrm{N}^{\mathrm{o}}$ de discussões & $\mathrm{N}^{\mathrm{o}}$ de pôsteres totais & Palavras \\
\hline \multirow{3}{*}{ Moda } & Look do dia & 21 & 176 & 4.855 \\
\cline { 2 - 5 } & Publicidade & 6 & 61 & 1.515 \\
\hline Total & & 27 & 237 & 6.370 \\
\hline
\end{tabular}

Fonte: Elaboração própria (2015) com base no Banco de Dados Netnográfico.

Na sequência, apresenta-se a Tabela

3 referente ao blog Garotas Estúpidas, onde também foi disponibilizada a quantidade de enredos, números de discussões e números de pôsteres totais.

Tabela 3 - Divisão do enredo desenvolvido para dar suporte à pesquisa (Garotas Estúpidas)

\begin{tabular}{c|c|c|c|c}
\hline \multirow{2}{*}{ Objeto } & Nome do enredo & $\mathrm{N}^{\mathrm{o}}$ de discussões & $\mathrm{N}^{\mathrm{o}}$ de pôsteres totais & Palavras \\
\hline \multirow{2}{*}{ Moda } & Look do dia & 3 & 37 & 1.174 \\
\cline { 2 - 5 } & Publicidade & 4 & 47 & 2.145 \\
\hline Mídias/ Youtube & Vlog & 2 & 52 & 912 \\
\hline Variedades & Dicas & 4 & 30 & 6.258 \\
\hline
\end{tabular}

Fonte: Elaboração própria (2015) com base no Banco de Dados Netnográfico. 
Realizando uma análise de conteúdo com os pôsteres dos participantes dos blogs, pode-se constituir a codificação das interpretações, para daí se realizar a categorização baseada nas características de valor, simbologia, percepções e interpretações utilizadas pelos consumidores no ambiente de estudo (KOZINETS, 2010). A interpretação dos significados dispostos pelos participantes dos blogs, permitiu a constituição das categorias dos usuários, que foram descritas nos resultados em função da teoria discutida, para formar perfis específicos de usuários, dado seus posicionamentos e percepções. Deste ponto, apresenta-se parte de alguns comentários, sendo os mais relevantes, para refletir e discutir sobre os valores identificados, fazendo assim uma relação teórica com os dados empíricos encontrados (AMARAL; NATAL; VIANA, 2008; DENZIN; LINCOLN, 2011).

\section{RESULTADOS}

Com base nos dados e interações coletadas dos blogs analisados, descrevemse abaixo as categorias de usuárias identificadas. Apresentam-se as análises com uma breve explicação sobre o grupo identificado, sendo em seguida dispostos alguns comentários feitos por leitores dos blogs, coletados por meio da netnografia, e por fim complementa-se com a literatura relacionada à categoria.

Foram identificadas cinco categorias de usuárias: "Apaixonadas e Devotas", que representam as leitoras que têm as blogueiras como inspiração; "Compradoras Potenciais", interessadas na compra dos produtos de um ponto de vista mais utilitário para a categoria plus size e mais hedônico para a categoria regular de consumidoras; "Frustradas", insatisfeitas com a escassez do mercado em relação à moda plus size; "Insatisfeitas com o blog", leitoras não satisfeitas com o conteúdo publicado; e "fashionistas", as que visitam o blog apenas para manter-se atualizadas com as novas tendências da moda e se concentram nas características hedônicas do processo e informações.

\subsection{Apaixonadas e devotas}

Nesta categoria, observa-se um grupo de usuárias que demonstram grande paixão/admiração pelas blogueiras, transformando-as em fonte de inspiração. Essa relação é tão forte, que as blogueiras estão se transformando em poderosas formadoras de opinião, capazes de 
influenciar o comportamento destas usuárias.

Segundo Bertolino (2010), “as pessoas famosas, sejam atores, cantores, personalidades em geral, passam a servir de espelho", e no caso das blogueiras, por terem adquirido grande prestígio nas mídias sociais, isto não é diferente.

\footnotetext{
“Como você é demais...demais...!! Me sinto poderosa quando leio suas dicas, seu posicionamento é sensato e uma injeção de autoestima. Te adoro, Ju!" (Blog plus size P-21 L 48-51)

"Ju você é fantástica, sigo mil outras blogueiras e sem dúvidas você é a mais autêntica, divertida e estilosa de todas plus size ou não. Mil beijos" (blog plus size P-8 L 14-17)

“Como sempre arrasa nos looks! Esse look é aquele pra se inspirar mesmo! Minha preferida! Não é à toa que faz sucesso no mundo inteiro rs. bjss!" (Blog regular P-16 L 10-15).
}

Outro fator que influencia nessa devoção das usuárias em relação às blogueiras é a forma intimista que a blogueira utiliza para se comunicar com suas leitoras. Ordunã (2007) afirma que a linguagem utilizada pelas blogueiras funciona, em algumas ocasiões como terapia e em outras como instrumento e identidade para a formação de vínculos sociais.

Bertolino (2010) reitera que a maioria das pessoas que acessam os blogs o fazem por acreditar que as blogueiras têm algo único a lhes oferecer e por confiar em suas publicações. A relação e interação entre as blogueiras e seus participantes leva a um sentimento de prazer, satisfação e carisma, o qual remete a valores hedônicos com características sociais, as quais levam a um posicionamento, status e segurança para o consumidor (ARRUDA FILHO;

CABUSAS; DHOLAKIA, 2008).

\subsection{Compradoras potenciais}

Esta categoria buscou analisar as usuárias que acessam o blog em busca de produtos que possam atender as suas necessidades (motivações utilitárias), principalmente quando falamos de consumidoras plus size, já que os blogs servem para elas como uma vitrine, onde, além da divulgação de uma grande quantidade de lojas e produtos, essas usuárias têm a certeza de que vão conseguir comprar o que lhes agrada.

Conforme afirma Silva (2011) os blogs de moda viraram um mercado de referência para quem procura sobre $\mathrm{o}$ tema. Grandes empresas estão de olho nesse público, pois estes blogs de moda servem como guias de estilos e estão também ligados ao consumo de moda, servindo de referência em possíveis compras. 
"Muito lindo o look, amei tanto que comprei tudo, e a bata meninas, as gurias da Rouge Marie Plus Size estão colocando no site ainda hoje...." (Blog plus size P-20 L 5-8)

“Amigas esse macacão ta no site da marca por $\mathrm{R} \$ 199,00 !$ !! Acabei de comprar o meu!" (Blog plus sizeP-6 L 12-14)

"Short saia esgotou no site! Juliana destruidora! Ahhahahahahaha" (Blog plus size P-14 L 3-5)

Outro grupo de possíveis compradoras potenciais, igualmente influenciado pelo o que é publicado nos blogs, é o daquelas que ao contrário das consumidoras plus size, possuem motivações hedônicas, ou seja, consomem para satisfazer seus desejos, característica esta observada com maior frequência nas leitoras de blogs de moda regular.

$\mathrm{O}$ ato de consumir é uma forma de comunicação entre as pessoas e de elas expressarem sua personalidade. É a forma de construção de um perfil diante da sociedade. "Você é o que consome e esses produtos te levam para determinada classe, sendo uma busca por integração social e ao mesmo tempo por uma individualidade" (MIRANDA, 2008).

\footnotetext{
"Ai ai ai assim eu enlouqueço de vez... Kkkkk, agora q consegui terminar meu "kit contorno" lá vou eu iniciar o "kit iluminador"! Hauahauha... Amei o post Cá! Mil bjos cheio de carinho... E agora, partiu Sephora fazer comprinhas!!! Hehehe" (blog regular P-4 L 50-55).

"Esse biquíni rosa e preto, e a bolsa prata e turquesa estão incríveis! Vou
}

correr pra Renner pra ver se encontro!" (Blog regular P-20 L 10-13).

Desta forma, é possível perceber que os blogs possuem grande influência no processo de consumir moda na rede, sendo utilizado pelos usuários inicialmente, para uma busca de referências, e em seguida para o consumo concreto. Esta categoria de usuários possui uma definição clara de posicionamento individual, no qual é uma relação também de status, porém com características mais do empoderamento do indivíduo (BATRA; AHTOLA, 1990)

\section{$5.3 \quad$ Frustradas}

Nesta categoria, identificaram-se as usuárias que se sentem prejudicadas e excluídas, devido à escassez na oferta de produtos plus size no mercado (SANDICKI E GER, 2010; SCARABOTO E FISCHER, 2013). A escassez reforça o estigma (ZANETTE, LOURENÇO, BRITO, 2013), já que quem não está "enquadrado" no padrão de magreza imposto pela sociedade automaticamente é excluído, pois é conveniente manter a invisibilidade destas mulheres, reproduzindo e alimentando o status quo da beleza (MORENO, 2014). "Ju, onde você compra meia calça??
Sempre tenho problema pq minha coxa e
grossa então não $\quad$ consigo 
achar..Lindaa..Dyva" (blog plus size, P-4 Linha 10-13)

“Ah, eu uso short jeans + coturno direto! Meu look favorito. Mas realmente é mega chato achar short jeans grande que não seja esses de senhora. Eu ainda uso um ou outro 46 que me cai bem, mas se aumentar um número já fica impossível. Adoro essas dicas de lojas com tamanhos grandes" (blog plus size P-9 L 11-17)

"Sinceramente horrível é ser gorda como eu, mole, cheia de celulite e estria. FEIO É PARECER UM BUTIJAO, sentir os pés doer num salto fino. Feio é ver as coxas ficarem suando no meio de tão grossas, FEIO é falar mal de algo que somos INCAPAZES DE TER.. eu, por mim, pesaria $40 \mathrm{~kg}$.. odeio meu corpo, meu cabelo e acho mts coisas feias por aí, MAS NAO FALO PQ NAO ME DIZ RESPEITO, mas feio mesmo É BARRIGA 100\% DE PRETUBERANCIA" (blog plus size P-21 L 32-41)

A diferenciação entre as pessoas com base em seu tamanho é uma forma inaceitável de discriminação contra um grupo estigmatizado (SOLOVAY, 2000).

Dessa forma, é importante que o mercado esteja atento às necessidades destas consumidoras e compreenda que o mercado deve se adequar a tais necessidades e não o oposto. Já que, ao não oferecerem escolhas de moda para mulheres gordas, os comerciantes violam a lógica comercial, abandonando possíveis lucros e responsabilidade para a sociedade (SCARABOTO; FISCHER, 2013).

\subsection{Insatisfeitas com o blog}

Nesta categoria, identificaram-se as usuárias insatisfeitas com o conteúdo publicado no blog e com a falta de interação entre a blogueira e os leitores, comportamento este observado exclusivamente nos leitores do blog de moda regular analisado nesta pesquisa, dada a não valorização destes usuários do blog em relação aos seus interesses pessoais.

"O ' "blog”, está cada dia mais chato. Não quero postar com nome pra não gerar bafafá com ninguém. É só uma opinião sincera. Poucos vídeos, só publipost atrás do outro (nessa page mesmo, leite de rosas, viagem pra Espanha, look com roupa patrocinada, aliás, look do dia já cansou). (Blog regular P-17 L 12-15)

"Perdendo a vontade de tá olhando todo dia como antes. Aliás, não vejo mais com tanta frequência, raramente perco algo. Que leiam com atenção e vejam como uma crítica construtiva". (Blog regular P-15 L 9-18)

"Camilla e o blog viraram pura futilidade. Antigamente entrava TODOS os dias no blog e agora não tenho mais essa vontade, o que é triste visto que acompanho o site há muuito tempo". (Blog regular P-15 L 20-24)

A falta de interação entre a blogueira e seus leitores é um ponto chave para a insatisfação observada nesta pesquisa. "Hoje em dia os consumidores, em sua maioria são proativos e não reativos como no passado" (MOURA, 2013), e esperam estabelecer 
uma espécie de relacionamento com a blogueira.

"Camila, gostei muito do batom, qual é? Parece com o mesmo que você usou no look junino do "Estrelas", na época também perguntei sobre o batom, mas você não respondeu os comentários". (Blog regular P-2 L 48-3)

Sendo assim, é crucial que o usuário perceba que seu comentário foi importante e se sinta motivado para comentar outras vezes (LUZ, 2009), pois embora o blog seja um lugar de auto expressão (YANG, 2011), esse discurso também é produzido com a participação dos leitores, configurando assim, uma realidade de "diálogos de produção cooperativa e discursiva" (LEITE, 2013). Fomentar a interação entre autor e leitor, principalmente através de comentários, é o segredo dos blogs (CORRÊA, 2010).

\section{$5.5 \quad$ Fashionistas}

Nesta categoria, buscou-se analisar usuárias que dão grande importância às marcas e às tendências da moda. Estas usuárias utilizam os blogs como meio de informação sobre o que está acontecendo no mundo da moda e, desta forma, buscam acompanhar o que acontece a cada momento.

O envolvimento com o blog, segundo Silva (2011), se torna um compromisso diário para quem os utiliza como modelo em pesquisa de estilos, com o objetivo de incorporar ao menos um elemento do que está na moda ao seu estilo. Silva (2011) afirma também "que nesse mundo de consumo de moda, mesmo que on-line, estar por dentro do que está acontecendo é estar em sintonia com o processo de renovação da moda".

"Passei o fim de semana babando nos looks pelo insta, mas esse Louboutin, realmente, caso de amor à primeira vista! Não tem como não apaixonar por uma peça dessa... " <3 Xoxo (blog regular P-15 L 26-32)

"Ai meu deus eu morri de amores nesses looks, e esse vestido então perfeito todo meigo, o crocs é algo realmente muito confortável e agora eles estão investindo em "estilo moderno" $e$ isso é ótimo para o mundo da moda jovem. Bonito e confortável tudo o que eu desejava "' (blog plus size P-3 L 24-29).

"Arrasou Ju, você juntou no look duas peças que amo, que são a parka e o colete, ainda mais com estampa étnica. Tá linda! Beijos!" (Blog plus size P-11, L 1822)

"Liiiinda! sempre fico babando por esse scarpin...\#ineeeeed” (blog regular P-15, L 49-51)

A moda está em constante modificação, desta forma as coleções são substituídas rapidamente e os consumidores precisam acompanhar as tendências (CARACIOLA, 2015). Sendo assim, as usuárias utilizam os blogs devido ao fácil acesso ao conteúdo, e como referência no processo de formação de estilo de cada leitor (SILVA, 2011). 
$\mathrm{O}$ indivíduo utiliza a roupa como forma de comunicar ao mundo a sua personalidade. Godart (2010) afirma que ao optar por determinada roupa ou acessório, este indivíduo constantemente reafirma sua inclusão ou não em um determinado grupo social, cultural, religioso, político ou profissional. Para Diana Crane (2006), a moda seduz por oferecer a possibilidade de se tornar diferente de alguma forma, mais atraente ou mais poderosa. Este alto valor social incorporado nesta categoria é parte de uma valorização hedônica, relacionada ao prazer, diversão e satisfação em estar atualizada, diferente dos outros e em geral posicionada de forma superior aos demais (FOXALL; YANI-DE-SORIANO, 2005; HARJU, 2015).

\section{CONSIDERAÇÕES FINAIS}

Nos últimos anos, houve um aumento considerável no uso dos blogs como uma nova mídia, dinamizando o modo como a informação circula na rede. Isso se deve à forma intimista em que é feita a comunicação entre blogueiras e leitoras. O estudo buscou compreender quais a influência e a efetividade dos blogs na decisão de compra do consumidor dos produtos de moda e se tais motivações são hedônicas ou utilitárias.
Após a análise dos dados coletados, confirmou-se que o blog Entre Topetes e Vinis, do segmento plus size, possui maior influência para a decisão de compra, pois as motivações das usuárias são fortemente utilitárias, fato este explicado pela escassez dos produtos correspondentes no mercado (SCARABOTO; FISCHER, 2013). Tal escassez reforça o estigma em torno das usuárias, gerando nelas uma sensação de frustração por não se enquadrarem no padrão estético imposto pela sociedade e pelo mercado da moda.

Essas usuárias acessam os blogs constantemente em busca de produtos que possam satisfazer suas necessidades e, ao encontrá-los, são direcionadas às lojas virtuais por meio de links disponibilizados pela própria blogueira. A compra é efetivada na maioria dos casos, o que se comprova pelo fato de que os produtos expostos no blog se esgotam com grande rapidez.

Com base nas informações analisadas no blog Garotas Estúpidas, escrito por Camila Coutinho, percebeu-se que a influência para a compra on-line exercida sobre as usuárias é menor e que as motivações de compra neste caso são predominantemente hedônicas. Além disso, o blog é utilizado muito mais como uma revista eletrônica, em que as leitoras, ditas fashionistas, buscam atualizações 
sobre as tendências de moda, já que a grande maioria dos produtos expostos é de grifes famosas de alto luxo e lançamentos das últimas coleções. Entretanto, isso gera, em algumas usuárias, uma insatisfação com o conteúdo publicado, pois não condiz com o perfil delas leitoras. Com efeito, uma das principais razões que as levam a acessar os blogs é a identificação, tanto com quem o escreve, quanto com o conteúdo publicado.

A devoção e admiração das usuárias em relação às blogueiras foi outro fator observado durante a pesquisa. Isso ocorre tanto no blog plus size, quanto no regular. As usuárias percebem na figura da blogueira uma fonte de inspiração, vendo-a até mesmo como um modelo a ser seguido. Em relação ao blog plus size, essa relação muitas vezes vai além, servindo em alguns casos como terapia, melhorando a autoestima, já que as dificuldades compartilhadas fazem com que as usuárias se sintam acolhidas e compreendidas em relação às suas inseguranças.

Finalizando, o estudo deixa como contribuição informações que podem servir para que as empresas observem os estímulos e as características de cada consumidor e aproveitem os benefícios que a plataforma oferece para o mercado da moda, já que associar sua marca a um blog de grande audiência pode trazer resultados positivos a longo prazo.

Entre as limitações encontradas está o número de pessoas participantes, já que a análise foi restrita a dois blogs. Para trabalhos futuros, sugere-se realizar a análise da influência de outras mídias sociais, bem como entrevistas ou aplicações de questionários a pessoas diretamente ligadas a essas mídias. 


\section{REFERÊNCIAS}

AMARAL, A.; NATAL, G.; VIANA, L. Netnografia Como Aporte Metodológico da Pesquisa em Comunicação Digital. Revista Famecos, Porto Alegre, no 20, dez, 2008.

ARRUDA FILHO, E. J. M; CABUSAS, J. A.; DHOLAKIA, N. Fator social versus tecnologia utilitária: marketing social versus marketing utilitário. Revista de Gestão da Tecnologia e Sistemas de Informação, v. 5, 2008.

ARRUDA FILHO, E. J. M.; SANTOS, A. J. C. d.; BRITO, E. P. Z. Technology Consumer Behaviour: A Study of Hedonic/Utilitarian Preference via Virtual Space. International Journal of Business Information Systems, v. 20, n. 4, 2015.

BATRA, Rajeev; AHTOLA, Olli T. Measuring the Hedonic and Utilitarian Sources of Consumer Attitudes. Marketing Letters, v. 2, no. 2, p. 159-170, 1990.

BENTO, Patrícia. A influência dos blogs no processo de decisão de compra. 2008: Disponível em: <http://www.marketingtecnologico.com/Artigo/a-influencia-dos-blogs-noprocesso-de-decisao-de-compra $>$. Acesso em: maio. 2015.

BERTOLINO, Isabela C. O poder das jovens blogueiras como formadoras de opinião na atualidade. Faculdade de Tecnologia e Ciências Sociais Aplicadas - FATECS, Brasília. 2010. Originalmente apresentado como trabalho de conclusão de curso, FATECS, 2010.

BOURDIEU, Pierre. Haute couture and haute culture. In: BOURDIEU, Pierre (Ed.). Sociology in Question. London: Sage, 1993.

CAMPBELL, C. A ética romântica e o espírito do consumo moderno. Rio de Janeiro: Rocco, 2001.

CARACIOLA, Carolina B. A influência da moda na sociedade contemporânea. In: MODA DOCUMENTA: MUSEU, MEMÓRIA E DESIGN, 50², 2015 São Paulo. Anais... São Paulo, 2015.

CLIFFORD, Stephanie. Plus-Size revelation: big women have cash too. New York Times, New York, 18 June. 2010.

COBRA, Marcos. Marketing e moda. Ed. Senac. São Paulo, 2008. 
COOPER. Charlotte. What's fat activism? Departament of Sociology Working Paper Series. University of Limerick, 2008.

CORRÊA, M. J. Comunicação digital: gêneros e multimodalidade aplicados à moda. In: CONGRESSO BRASILEIRO DE CIÊNCIAS DA COMUNICAÇÃO NA REGIÃO NORDESTE, 9 , 2010, Campina Grande-PB. Resumos. Campina Grande-PB, 2010.

COUTINHO, Camila. Garotas estupidas por Camila Coutinho. 2012. Disponível $\mathrm{em}:<\mathrm{http}: / / \mathrm{www}$.garotasestupidas.com/sobre-camila-coutinho/>. Acesso em: 11 jun.

CRANE, Diana. A moda e seu papel social: classe, gênero e identidade das roupas. Tradução de Cristina Coimbra. São Paulo: Editora Senac São Paulo, 2006.

DE CARLI, Ana M. S. O sensacional da moda. $1^{\text {a }}$ ed. Caxias do Sul: Educs, 2002.

DENZIN, Norman. K.; LINCOLN, Yvonna, S. The Sage Handbook of Qualitative Research. $4^{\text {st }}$ ed., Sage Publications: Los Angeles, US, 2011.

E-BIT Empresa de inteligência de comércio eletrônico. Relatório Webshoppers 2018. $37^{\mathrm{a}}$ Ed., 2018.

EUROMONITOR. The Plus-Size Market: clothing and footwear-USA. September, 2009.

FERNANDES, Gutemberg. Atração de púbico alvo, a importância do conteúdo relevante. 2014. Disponível em: <http://conexaoagencia.com.br/atracao-de-publico- alvo-a-importanciado-conteudo-relevante>. Acesso em: 27 out. 2015.

FERREIRA, Aletéia; VIEIRA, Josiany. A moda dos blogs e sua influência na cibercultura: do diário virtual aos posts comerciais. Revista Nacional dos Programas de PósGraduação em Comunicação, Pelotas-RS, maio 2007.

FOXALL, G. R.; YANI-DE-SORIANO, M. M. Situational influences on consumers' attitudes and behavior. Journal of Business Research, v. 58, nº 4, 2005.

GODART, Frédéric. Sociologia da Moda. São Paulo: Editora Senac, 2010.

GOFFMAN, Ervin. Stigma: notes on the management of spoiled identity. New York: Touchstone, 1986. 
GOSWAMI, Shubham. A Study on the Online Branding Strategies of Indian Fashion Retail Stores. Journal of Brand Management, v. 12, n. 1, p. 45-59, 2015

HAMESTER, Morgana; MORAES, Ana L. C. Somos todos convidados? Iara - Revista de Moda, Cultura e Arte, São Paulo, nº 1, v.4, abril, 2011.

HARJU, Anu A. Fashionably Voluptuous: Normative Femininity and Resistant Performative Tactics in Fatshion Blogs. Journal of Marketing Management, v. 31, n. 15-16, p. 1602$1625,2015$.

KARSAKLIAN, Eliane. Comportamento do consumidor. São Paulo: Editora Atlas, 2000.

KHAN, U.; DHAR, R.; WERTENBROCH, K. A Behavioral Decision Theoretic Perspective on Hedonic and Utilitarian Choice. In Inside Consumption: Frontiers of Research on Consumer Motives, Goals, and Desires (2005), ed. S. Ratneshwar and David Glen Mick, London: Routledge, 144-165, 2005.

KOZINETS, R. V. The field behind the screen: using netnography for marketing research in online communities. Journal of Marketing Research, nº 39, February, 61-72, 2002.

KUNST, Marina H.; ROCHA, Maria A. V. Consumo de moda praia, surfwear e magazine:o que deve ser priorizado? In: COLÓQUIO DE MODA, $8^{\circ}$, 2012, Rio de Janeiro. Anais... Rio de Janeiro: Fórum das Escolas de Moda, 2012.

LEITE, L. B. de A. A voz do leitor no blog Shameonyou, blogueira! Universidade de Brasília, Brasília, 2013. Originalmente apresentada como monografia de graduação, UNB, 2013.

LIMA, Paula G. Moda, necessidade e consumo. Actas de Diseño. Buenos Aires, Argentina, Ano V, nº 9, jul. 2010,

LIPOVETSKY, G.; ROUX, E. O Luxo Eterno: da idade do sagrado ao tempo das marcas. São Paulo: Cia das Letras, 2008.

LIPPERT, Denner. A relação e-commerce moda e rede sociais. 2013. Disponível em: <http://webfashionmarketing.com/index.php/a-relacao-e-commerce-moda-e-redes-sociais>. Acesso em: 20 jun. 2015. 
LUZ, Adriano. Como conseguir comentários em seu blog. Disponível em: $<$ http://www.gerenciandoblog.com.br/2009/03/como-conseguir-comentarios-em-seublog.html>. Acesso em: 27 out. 2015.

MALIK, G.; GUPTHA, A. An empirical study on behavioral intent of consumers in online shopping. Business Perspectives and Research. 2013.

MEDEIROS, B.; LADEIRA, R.; LEMOS, M.; BRASILEIRO, F. A influência das mídias sociais e blogs no consumo da moda feminina. In: XI SIMPÓSIO DE EXCELÊNCIA EM GESTÃO DE TECNOLOGIA, 2014, Resende-RJ. Arquivos eletrônicos. Resende-RJ: AEDB, 2014.

MELO, Jaqueline F. H.; ROCHA, Maria A. V. Silhuetas e corpos na maturidade: como vesti-los? Revista Brasileira de Economia Doméstica, Viçosa-MG, v.22, nº 2, 2011.

MERRIAM-WEBSTER DICTIONARY. Fashionista, 2010. Disponível em: <http://www.merriam-webster.com/dictionary/fashionista>. Acesso em: 2015.

MESQUITA, Laís R. A publicidade nos blogs de moda. Juiz de Fora-MG: UFJF, 2012. Originalmente apresentado como Trabalho de Conclusão de Curso, Universidade Federal de Juiz de Fora, 2012. Disponível em: <http://www.ufjf.br/facom/files/2013/05/A-publicidadenos-blogs-de-moda-Lais- Mesquita.pdf>.Acesso em: 20 maio 2015.

MOREnO, Tania V. A. A Constituição dos Sentidos da Mulher "plussize". Universidade Estadual de Mato Grosso do Sul. 2014.

MOURA, Luana M. A influências dos blogs de moda no processo de decisão de compra dos consumidores Natalenses. Universidade Federal do Rio Grande do Norte, Natal, 2013. Originalmente apresentado como trabalho de conclusão de curso, UFRN, 2013. Disponível em:〈http://monografias.ufrn.br:8080/jspui/bitstream/1/657/1/LuanaMM_Monografias.pdf>. Acesso em: 2015.

MUNIZ, Letícia. Moda é o setor que mais interage nas ações digitais. Revista Exame, 15 mai. 2012. Disponível em: <http://exame.abril.com.br/marketing/noticias/moda-e-o-setor-quemais-interage-nas-acoes-digitais-diz-pesquisa>. Acesso em: 15 jan. 2015.

NANNI, Henrique; CAÑETE, Karla. A importância das redes sociais como vantagem competitiva nos negócios corporativos. 2010. In: Congresso Virtual Brasileiro de Administração, $12^{\circ}, 2015$. Anais eletrônicos. 
NARCIZO, Bruna. Blogueiras cheias de estilo. Isto é Gente. São Paulo, nº 571, agosto 2010.

NEVES, J.L. Pesquisa qualitativa: características, usos e possibilidades. Caderno de Pesquisas em Administração, v.1, nº 3, 1996.

OKADA, E. M. Justification Effects on Consumer Choice of Hedonic and Utilitarian Goods. Journal of Marketing Research, Vol. 42, Issue 1, p. 43. 2005.

ORDUNÃ, Otavio Rojas; ALONSO, Junior; ANTUNEZ, José Luiz. Blogs: revolucionando os meios de comunicação. São Paulo: PIONEIRA THOMSON LEARNING, 2007.

PETERS, Lauren D. You are What You Wear: How Plus-Size Fashion Figures in Fat Identity Formation. The Journal of Dress, Body \& Culture, v. 18, n. 1, p. 45-71, 2014.

PINTO, M. J. Blogs! Seja um editor na era digital. São Paulo: Érica, 2002.

ROCHA, E. Culpa e prazer: imagens do consumo na cultura de massa. Comunicação, mídia e consumo, São Paulo, vol. 2, nº 3, 2005.

ROSA, Helaine A. Comunicação, mercado e mundo virtual: tendências para a próxima década. Razón y Palabra. México. nº 59, jun. 2015.

SANDICKI, Ö; GER, G. Stigma, identity and consumption. In: RUVIO, A. A; BELK, R. W. (Ed). The Routledge companion to identity and consumption. New York: Routledge, 2013.

Veiling in style: how does a stigmatized practice become fashionable? Journal of Consumer Research, v. 37, nº 1, p. 15-36, 2010.

SCARABOTO, D. Comunidades virtuais como grupos de referência nos processos decisórios do consumidor. Universidade Federal do Rio Grande do Sul, Porto Alegre, 2006. Originalmente apresentado como dissertação de mestrado, UFRS, 2006. Disponível em: <http://www.lume.ufrgs.br/handle/10183/6654>. Acesso em: 2015.

SCARABOTO, D; FISCHER, E. Frustrated fatshionistas: an institutional theory perspective on consumer quests for greater choice in mainstream markets. Journal of Consumer Research, v. 39, no 6. 2013. 
SHETH J. N; MITTAL, B.; NEWMAN B. I. Comportamento do cliente: indo além do comportamento do consumidor. São Paulo: Atlas, 2001.

SIGNATURE9. The 99 most influential fashion \& beauty blogs. Disponível em: <http://www.signature9.com/style-99>. Acesso em: 13 jun. 2015.

SILVA, Carolina H. B. P. O consumo dita a moda: percepções sobre os usos do blog shoelover. UNIFRA. Santa Maria-RS. 2011.

SILVA, Tomaz T. da. A produção social da identidade e da diferença. In: HALL, Stuart; WOODWARD, Kathryn. (org.). Identidade e diferença: a perspectiva dos estudos culturais. Petrópolis: Vozes, 2000.

SIQUEIRA, H. S G. Cultura de consumo pós-moderna. Disponível em: <http://www. angelfire.com/sk/holgonsi/consumismo2.html>Acesso em: maio. 2007.

SLAMA, M. E., \& SINGLEY, R. B. Self-monitoring and value-expressive vs. utilitarian ad effectiveness: why the mixed findings? Journal of Current Issues \& Research in Advertising, Vol. 18,1996.

SOLOVAY, Sondra. Tipping the scales of justice: fighting weight-based discrimination. Amherst, NY: Prometheus Books, 2000.

STEARNS, Peter. Fat history: bodies and beauty in the modern west, New York: New York University Press, 1997.

TECHNORATI. Relatório Anual de Influência Digital. Disponível em: <http://www.technorati.com>. Acesso em: 22 maio. 2015.

VAN DER HEIJDEN, H. User acceptance of hedonic information systems. MIS Quarterly, vol. 28, 2004.

VOGUE UNITED KINGDOM. Lagerfeld's high street split. November 18, 2004. Disponível em: <http://www.vogue.co.uk/news/2004/11/18/lagerfelds-high-street-split>. Acesso em: 2015.

WHITE, Harrison. Identity and control: a structural theory of social action. Princeton, NJ: Princeton University Press, 1992. 
WILSON, Eric. Bloggers crash fashion's front row. New York Times, December 24, 2009.

YANG, K. C. C. The effects of social influence on blog advertising use. Intercultural Communication Studies, Texas-USA, v. 2, nº 20, 2011.

ZAMBERLAN, L.; FROEMMING, L. M. S.; PRÊTO, L. F.; PRÊTO, M. B. A perspectiva hedonista no consumo de moda: uma investigação cross-cultural entre brasileiros e argentinos. XXXIV Encontro da ANPAD, Rio de Janeiro: 2010. Disponível em: <http://www.anpad.org.br/admin/pdf/mkt2425.pdf>. Acesso em: 9 maio. 2015.

ZANETE; L. E B. O peso do varejo, o peso no varejo e a identidade: uma análise de consumidoras plussize. RAE, São Paulo, v. 53, nº 6, nov-dez 2013.

ZARA, André. Sinônimo de elegância. Conexão SEBRAE. São Paulo: SEBRAE, n.31, p.7-9, dez. 2013. 